\title{
472836 - ANESTHESIA FOR DAY CASE CRANIOTOMY
}

\section{Lakshmikumar Venkat Raghavan, MD FRCA ${ }^{1}$, Pirjo Manninen, MD FRCPC ${ }^{1}$, Mark Bernstein, MD,FRCSC ${ }^{2}$ \\ 1. Anesthesia, Toronto Western Hospital, Toronto, ON, Canada \\ 2. Neurosurgery, Toronto Western Hospital, Toronto, ON, Canada}

Introduction: Day surgery procedures account for 70\% of elective surgeries in some specialities1. In contrast, Neurosurgical patients are mostly inpatients utilizing hospital resources. Day surgery neuroanesthesia is a new concept that requires change in surgical and anesthetic techniques. The aim of our study was to review the anesthetic management of patients undergoing day surgery craniotomy for supra-tentorial brain tumors Methods: After ethics board approval, we reviewed 100 consecutive patients from Feb 2003 - Dec 2007 who underwent day surgery craniotomy for brain tumor. The surgeon assigned the day surgery status prospectively. The data collected included patient demographics, anesthetic technique used and perioperative complications Results: Ninety-one patients had awake craniotomy (AC) and 9 had general anesthesia (G/A). All the patients were seen in preoperative anesthesia clinic. Location of tumor, patient cooperation, the need for intraoperative testing determined the choice of anesthesia (awake vs. G/A). All the patients arrived in the morning of surgery and discharged before 1800 hrs. The mean age was 50yrs (range 19-80 yrs), 55 male 45 female. Mean duration of procedure was $160 \mathrm{~min}$ (range 80 to $250 \mathrm{mins}$ ). All G/A patients (9) had their airway intubated. No airway manipulation was used in AC patients except for oxygen delivery through nasal prongs. Sedation used in AC patients included propofol $(n=87)$, fentanyl $(n=85)$, midazolam $(n=85)$ and remifentanil $(n=80)$. There were no intraoperative conversion from AC to G/A. All the patients stayed in the recovery room for 4 hrs and then had a head CT scan to rule out any complication. Successful discharge from day surgery unit was possible in $96 \%$ of patients. Four patients were converted to inpatient status due to seizures (2), nausea and anxiety (1) and new neurological deficit (dysphasia)(1). Average time of discharge from hospital was 6hrs after surgery.

Discussion: In our experience, day surgery craniotomy is a safe and cost effective technique for a carefully selected group of patients with supratentorial tumors

References: 1. Can J Anesth 1998; 45:R76-83. 